Recibido: 1 Diciembre / Aceptación: 20 Diciembre

Ensayo

\title{
Arte indígena actual: Apertura o resistencia
}

\author{
Rocío Polanía Farfán \\ Docente Asistente \\ Universidad Surcolombiana \\ rocio.polania@usco.edu.co
}

Las propuestas artísticas creadas al margen de la estética occidental, representadas en este caso en la producción que vienen generando algunos artistas de procedencia indígena, permiten pensar su producción artística como un espacio de resistencia, un esfuerzo por liberar las mentes de estereotipos y reacciones mecánicas impuestas por las nociones e instituciones culturales, sociales, políticas éticas y estéticas dominantes. El arte indígena actual, sin renunciar a su identidad, reelabora mitos, símbolos y diseños para generar un estilo inspirado en sus tradiciones pero capaz de ser incluido dentro del contexto artístico contemporáneo.

El arte indígena como objeto estético es capaz de dialogar con las prácticas artísticas que se desarrollan en el mundo globalizado, pues plantea actitudes de indisciplina frente a las construcciones culturales y racionales de la civilización euroamericana. Está llamado entonces a redimensionarse en el contexto cultural global como movimiento artístico incluyente y contemporáneo que intenta romper las ideas predominantes para encontrar nuevos significados a la vida, trascender fronteras, desatar la imaginación, y liberar esos mundos intangibles, volátiles e inaprensibles que han permanecido en resistencia.

Así el arte indígena crea sistemas que dialogan con la realidad artística actual e interactúan con sus formas de expresión de manera alternativa. Tradicionalmente la producción artística indígena ha sido la representación de la otredad. No obstante, esa producción circula a contramano con los paradigmas y discursos hegemónicos de sistema-arte que la ubican al margen de los centros, en el lugar del otro, justo en el borde donde la hermenéutica decolonial reclama un giro por la relocalización del locus de enunciación.

Este lugar permite incorporar distintos hablantes, saberes, modos de expresión, dos espacios que se contraponen, se niegan y se complementan al mismo tiempo. El sujeto enunciador heterogéneo responde a su realidad y condición intercultural, y a pesar de su competencia bicultural no logra integrarse, hacer una síntesis, sino que opta por una de sus herencias o por evidenciar esa tensión no resuelta. La presencia de múltiples voces se puede detectar en las distintas expresiones estéticas bajo la forma de pluralidad, es decir, varias voces en correspondencia con múltiples conciencias independientes y únicas, no reductibles entre sí.

Ticio Escobar al referirse al arte indígena propone "la necesidad de replantear sobre bases más complejas, la relación entre las particularidades y los universales exige, pues, concebir ambos términos no como referentes autónomos ni como momentos de una relación bipolar sino como fuerzas variables cuyo interjuego moviliza negociaciones y supone reposicionamientos, avances y retrocesos, conflictos no siempre resueltos, soluciones provisionales, inesperadas (...). Estas mediaciones deben no sólo garantizar la diversidad sino propulsar condiciones aptas para la confrontación intercultural; y deben alentar la posibilidad de que el derecho de las identidades coexista con miradas de conjunto. Miradas que permitan construir proyectos compartidos por encima del inmediatismo de las demandas particulares y que puedan coordinar discursos y prácticas disgregadas sin sustantivizar la totalidad ni arriesgar las diferencias"1.

Desde la mirada de Escobar hay que pensar el arte indígena no como una cuestión identitaria, sino más bien como un conjunto de prácticas que borra fronteras, pero que potencian prácticas de acercamiento y ruptura. En este sentido, "el sujeto creador remueve las capas colonizadoras de la estética normativa occidental y adquiere o crea sus propios principios estéticos, emanados de su propia historia local, de su geo y corpopolítica del conocimiento. Un individuo que se comunica con un arte de ese talante aprende a abarcar la enormidad del anti-sublime decolonial y a identificarlo en su totalidad". Esto significa "que libera la percepción para empujar al sujeto hacia el agenciamiento -ético, político, social, creativo, epistémico, existencial... significa también, una apuesta por aquellas otras formas estéticas y culturales que la modernidad excluyó, negó, ignoró, consideró como insignificante, sin sentido y bárbaras" ${ }^{2}$.

1 - Escobar, Ticio. Identidades en tránsito. Centro Teórico Cultural. En http://www.pacc.ufrj.br/artelatina/ticio.html.

2 - Madina Tlostanova Universidad Rusa de la Amistad de los Pueblos. Doctora en filología, profesora de historia de la filosofía y directora del Centro para Estudios Transculturales en la universidad Rusa de la Amistad de los Pueblos en Moscú. Madina Tlostanova es una académica transdiaspórica que ha enseñado e investigado en múltiples instituciones internacionales (Instituto de Estudios Postcoloniales y Transculturales de la Universidad de Bremen, Centro para Estudios Globales y Humanidades de la Universidad de Duke, etc). Su trabajo se centra en la opción decolonial y las humanidades. Ha escrito siete libros y numerosos artículos sobre estética, ficción, subjetividad, filosofía transcultural y género (entre ellos, Epistemologías de género y la zona fronteriza euroasiática, Palgrave MacMillan, 2010 ). 
Bajo la mirada de Tlostanova es importante dilucidar que con el hecho de resistirse a la lente occidental no se está llamando al retorno a una identidad pura, esencialista, ni a un arte originario. El arte indígena actual no es simplemente un fenómeno instintivo orientado al reconocimiento de lo propio: los objetos estéticos indígenas contienen la presencia de elementos espirituales, el reflejo de visiones cosmogónicas, así como las maneras propias de interpretar la realidad existente.

Un ejemplo de esto es el conjunto de obras de Domingo Cuatindioy, producto de procesos creativos provenientes de sonidos, palabras, colores, formas emanadas del contexto, lo cual permite crear las condiciones para que los pueblos hablen con voz propia; es decir, para expresar sus propios resonancias y pronunciar sus palabras sin las presiones ni aberraciones impuestas por los otros. Es un proceso de autodescubrimiento, un juego de conceptos, fuera y dentro, donde se encuentra la clave de la relación intercultural problematizada a través de los símbolos que le rodean y magnifican su expresión.

La obra de Cuatindioy es un propósito firme de romper con las fuerzas gravitacionales ejercidas por el arte eurocéntrico. Al respecto, Adolfo Colombres afirma que no es necesario seguir imitando la cultura dominante a través de la incorporación de elementos ajenos, sino más bien impulsar proyectos en procura de la recuperación de la cultura propia, del arte, del pensamiento histórico y simbólico. Invita, además, a repensar el sentido adverso como se ha venido tratando la tradición cuando se conceptualiza como cerrada, reiterativa, sin tomar en cuenta los procesos de cambio. La tradición no es una cárcel o un sistema de mecanismos automáticos; no es un autorrepliegue, enclaustramiento, remedo mimético o sumisión cultural. La tradición ha de ser un sustrato, no una presión o un someterse a mecanismos ciegos.

En este contexto la propuesta de Cuatindioy permite escuchar los murmullos de la naturaleza traducidos a mundos superpuestos que despiertan las potencias dormidas de las cosas, y las inviste de sorpresa y extrañeza; las aleja, quebranta su presencia ordinaria y las arranca de su encuadre habitual para enfrentarlas a la experiencia, inconclusa siempre, de lo extraordinario. Lo abstracto $y$ figurativo se mixturan para acercar al espectador a una lectura profunda de los orígenes de su mundo. Los relatos susurrados percibidos en su obra se constituyen en el referente en el cual se reconoce el artista, con ellos se identifica y encuentra la confianza en sí mismo para reafirmarse en el lugar a que pertenece.

La obra de Cuantindioy es el yo múltiple (Guasch, 2005), la complementariedad propia, donde surge un sinnúmero de hilos que tejen un mundo simbólico producto de las relaciones interculturales. La intensidad de las imágenes, la fascinación de los colores, así como la luminosidad, la composición y las formas inquietantes contribuyen a expresar la complejidad y las preocupaciones de su pueblo. La incertidumbre se hace visible a través de la suspensión del punto en su relato subalterno rebosante de preguntas sin respuesta.

De este modo el reconocimiento de un arte distinto permite reivindicar de alguna manera a los pueblos indígenas, afirmar su territorio simbólico para garantizar su derecho a la diferencia, así como la posibilidad de vivir, pensar, creer y crear de manera propia. El arte indígena comprendido como un espacio para la creación de formas alternativas, dinámicas y distintas a partir de su propia historia, se constituye en un punto de referencia que anticipa modelos sustentables de porvenir y autoafirma un referente

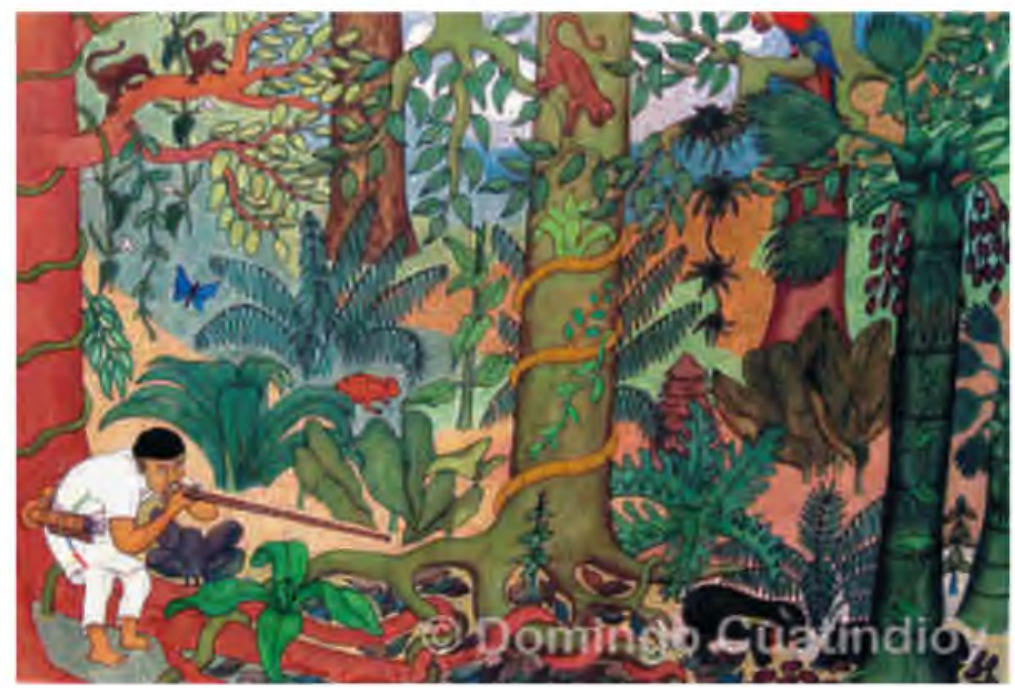

El cazador (Metsästäjâ). Domingo Cuatindioy, $2009^{3}$.

3 - MYYNTIKOKOELMA. Taita Domingo Cuatindioy http://www.myyntikokoelma.fi/public/go.php?action=works\&filter=artist_id\%3D18174. Consultada 03/03/2014 
fundamental de identificación colectiva, así como un componente de cohesión social, un factor de resistencia cultural y un lugar de discusión política.

En esta medida conservar la cultura no significa repetir los modelos antiguos. La tradición no está privada del ejercicio de la imaginación creadora, en la que se puedan concebir nuevas formas a partir de las precedentes. Por ello resulta significativo "tener en cuenta los criterios de los teóricos latinoamericanos Roberto Fernández Retamar, Néstor García Canclini, Adolfo Colombres, Juan Acha, Ticio Escobar, quienes acérrimamente han atisbado el peligro que representa la extrapolación de modelos nacidos dentro de la tradición del pensamiento occidental para estudiar las prácticas artísticas generadas desde los diferentes espacios latinoamericanos, pues si bien es cierto, dichas prácticas son inherentes al objeto o al hecho artístico y responden a criterios asociados al contexto sociocultural donde se desarrollan. En consecuencia, ningún arte verdadero se da al margen de todo grupo social, de un contexto cultural que le confiera sentido (Colombres, 1991).

Para el caso, en la Región Surcolombiana el arte indígena da lugar a pensar que las prácticas estéticas descansan exclusivamente en valores construidos a partir del origen de sus propias culturas. Sin embargo el artista de esta región interrelaciona valores plásticos, claves conceptuales, marcas de contexto o referencias a la realidad para alcanzar un nivel cada vez más visible y constante en el ámbito nacional e internacional.

La producción artística de los últimos años en la Región señala claramente cómo los artistas de origen indígena buscan reemplazar las preocupaciones formales por otras arraigadas en el contexto sociocultural de su procedencia. Desde esta perspectiva la obra surge como el resultado de un proceso de construcción o interrelación particular con el contexto, para liberarla de su designio representativo y el valor objetivo de la forma, para pasar a ser considerado un proyecto que reclama una captación perceptual diferente dirigida a incursionar en los terrenos adversarios y tomar de ellos argumentos nuevos para corroborar sus particularidades. En esta vía las prácticas estéticas ejercidas por los creadores indígenas de la Región proponen establecer una diferencia cultural, no como mera reacción o resistencia defensiva, sino como gesto político afirmativo, obediente a sus propias estrategias.

Un ejemplo de una visión indisciplinada del arte es la obra de Kindi Llajtu, quien con su sencillez, simplicidad y carácter íntimo vincula la memoria del pasado como un lugar de tensión y negociación continua. Llajtu, en este campo de disputas y resistencias, presenta la paradójica relación entre lo tribal, totémico, etnológico, cultural, místico y artesanal con lo nuevo, lo que exige otros juicios para su comprensión. No obstante, en esa dialéctica lo intercultural se presenta como una continuidad del proceso de resistencia de los sujetos frente a las amenazas y peligros que se entretejen en las nuevas formas de colonización. Llajtu ve en su obra una afirmación de la identidad, un lugar donde se acepta al culturalmente distinto y se propicia un espacio para el enriquecimiento mutuo: un lugar donde se aprende de los unos y de los otros.

Para Llajtu, las canoas son un auténtico símbolo, no son un mero signo capaz de mediar entre la imagen y el concepto, sino la realidad revelada de un proceso rígido en el que ellas se constituyen per se en lo significado y la significancia. En la obra "Pescador" el artista expresa los secretos del orden cósmico, o modelo universal que el artista desentraña y traduce a un lenguaje adaptado a las necesidades, imágenes y

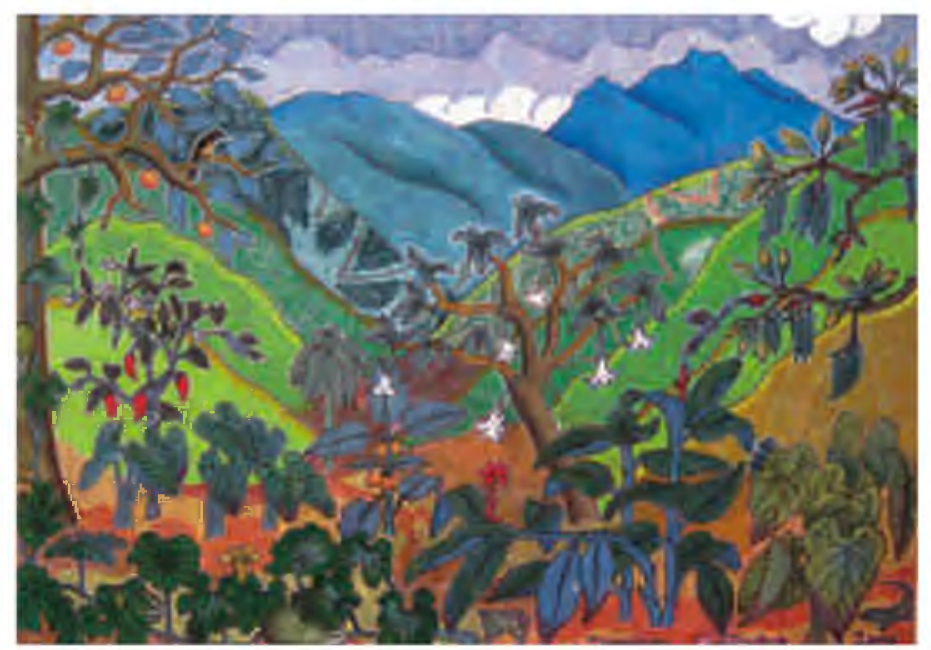

Volcán Patascoy (Patascoy-tulivuori). Domingo Cuatindioy, $2009^{4}$.

4 - HELSINGINTAITEIL.IJASEURA. Taita Domingo cuatindioy http://helsingintaiteilijaseura.fi/nayttelyt/ambingaba-shamaanitaidettakolumbiasta/attachment/cuatindioy/. Consultada 03/03/2014 
vivencias del cuerpo social y el individuo. Orden constituyente, además, del origen del pensamiento, y de las estructuras e imágenes de los procesos históricos y culturales de las comunidades del sur de la Región. Sugiere también la creación de espacios, tiempos, imaginarios y símbolos armonizados, a partir de canoas cuidadosamente intervenidas con fibras de diferentes materiales, y con sonidos que evocan el entramado de la diversidad cultural y del complejo tejido social.

Ante el deseo de resemantizar el arte en la Región, las prácticas artísticas y culturales indígenas obedecen a un criterio de resistencia que traspase los valores absolutos y perennes impuestos por la hegemonía occidental a lo largo de la historia de la cultura en América Latina. En este contexto se busca un planteamiento más próximo a las realidades sociales de las culturas regionales, un espacio para la pregunta que permite develar otros significados de la realidad. Obviamente el artista indígena acepta, sustrae imágenes y conceptos del mundo globalizado, en la medida de su utilidad para sus propias historias. Cuando lo realizan con imaginación y convicción provocan resultados legítimos y auténticos.

En este escenario Colombres propone construir una teoría americana del arte, la cual "debe arrancar de lo indígena y lo popular, como una historia crítica de las formas visuales de un país o región; debe centrarse en la modernidad, dado que el mismo fenómeno del arte es de origen occidental y moderno; debe prestar especial atención a los mitos, tomándolos como fundamentos de la cultura; debe prestar especial atención a las formas de penetración que buscan colonizar el imaginario; debe defender el territorio como soporte del pensamiento y un elemento de especial importancia en la producción de sentido; debe tomar distancia del legado idealista y burgués que signa a la estética occidental prestigiando al individuo en la medida en que su obra alcance a representar los valores o conflictos de su comunidad o se sitúe de forma crítica en el proceso histórico de ella; debe abrirse a la idea de que forma y función se complementan, y la existencia de una función no estética en una obra no le niega su calidad de artística" (Colombres, 2001: 222).

Al respecto, Roberto Kusch hace un llamado a dar un salto a otra racionalidad (Azcuy: 7), una capaz de integrar al sujeto personal en un nosotros y de concebirlo dentro de un tiempo-espacio propio, restaurando una relación de pertenencia cósmica, una geocultura. El propósito sería entonces el de construir un pensamiento idóneo para dar cuenta de su realidad integral, que no sólo busque mirar hacia adentro sino también desde la posición del otro, para de esta manera "ponernos en condiciones de recuperarnos a nosotros mismos en tanto hombres nuevos y salvos" (Betancourt, 1985: 73).

En este territorio de cruces la apuesta estaría dada por la elaboración de un pensamiento decolonial centrado en otras maneras de entender el mundo como proceso constructor de significados colectivos; una forma de entretejido cultural y social expresada en las distintas formas de visualizar procesos humanos en donde unos sujetos se reconectan con otros, lo cual, según Kusch, plantea un desafío al entendimiento: "para comprender una cultura es necesario el sujeto que ve el sentido como también el que lo crea" (Kusch, 1975: 115). Así, no se trata solamente de la inclusión de prácticas estéticas de unas culturas dentro de las otras, sino también de la apertura o la extensión por parte de la cultura occidental dentro de su propia concepción de arte, para establecer un diálogo incesante entre unas y otras.

En relación con lo anterior el artista Benjamín Jacamanijoy Tisoy, empleando formas, colores y texturas, propone expresar no sólo una voz personal, sino también una explosión de identidades colectivas forjadoras de un arte de retorno a sus orígenes para reencontrarse con identidades perdidas y, simultáneamente, generar nuevos contenidos de su herencia cultural. Jacamanijoy, a través de su obra, siente la necesidad de redimensionar el aporte indígena en el

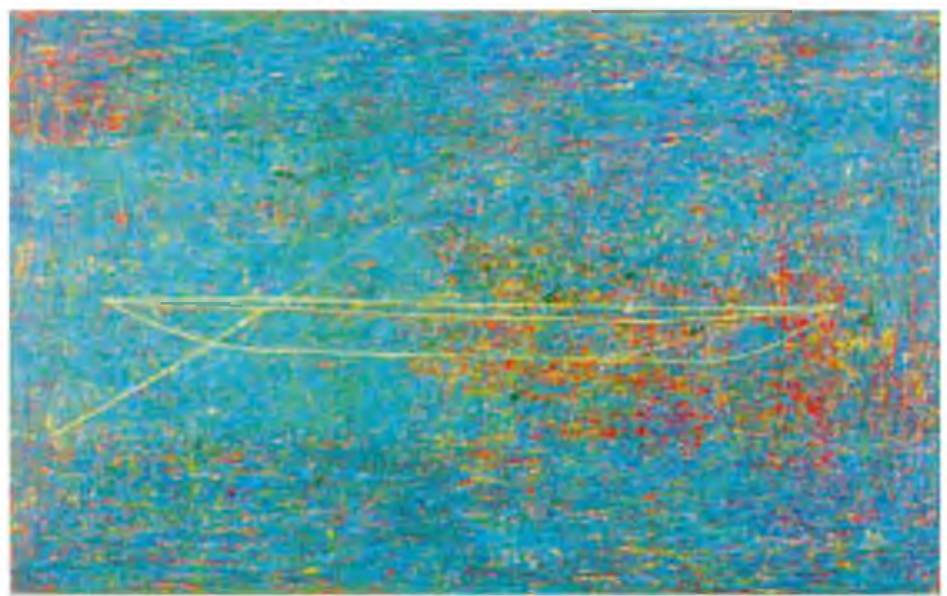

Río abajo. Kindi Llajtu, $2005^{5}$

5 - COLARTE. http://www.colarte.com/colarte/foto.asp?idfoto=221435. Consultada 08/03/2014 
arte y la cultura global, como parte del mundo artístico incluyente y contemporáneo que intenta romper las ideas predominantes y encontrar nuevos significantes para restituir los valores negados. Bajo esta mirada la propuesta de Jacanamijoy se ubica en los bordes, deshace espejismos, redime realidades imperceptibles, sutiles e inaccesibles, a fin de establecer posibles intersecciones con otras realidades.

Pero tales intersecciones entre lo no-occidental y lo occidental no implican, en palabras de Ticio Escobar, "que al asumir esa doble vertiente, supone el reto de renunciar tanto a los universalismos de signo totalitario como a la dispersión y el encapsulamiento de las identidades; ambos extremos bloquean el desarrollo de políticas democráticas. De lo que se trata es que las identidades mantengan abierto su horizonte de ciudadanía y de polis: que ni sean arrasadas por la globalización ni se conviertan en nuevos particularismos mesiánicos y autosuficientes" (Escobar, 2012).

Desde esta mirada se desprende entonces que la producción artística indígena actual está en desplazamiento constante, no se ata ya a un territorio especifico y se moviliza por medio de redes transculturales en las cuales experimenta una entrada definitiva a los discursos particulares. Estos últimos marcan otras formas de lectura del arte, y campos de acción más allá de un territorio o de los orígenes. Tales lecturas buscan un supuesto real presente en la verdad del otro, para de esta manera ubicar su participación en el concierto del arte contemporáneo.

Es evidente encontrar en el arte indígena un estado de liminalidad en cuyo interior se confrontan diferencias, heterogeneidades, circulan imágenes, transitan formas simbólicas, y objetos varios que retratan y materializan las dinámicas socioculturales y cosmogónicas de una cultura que teje sus contenidos estéticos en una amena conversación entre sus tradiciones y su incursión en las dinámicas del arte actual.
Un arte así no se limita a recordar el pasado como causa social o precedente estético, se orienta más bien a la renovación del pasado refigurándolo como un espacio "entre-medio" contingente que innova e interrumpe la performance del presente. El "pasadopresente" se vuelve parte de la necesidad, no la nostalgia de vivir. Llega entonces el momento de la distancia estética que provee al relato de un doble filo: como sujeto latinoamericano mestizo es una hibridez, una diferencia "interna", un sujeto habitante del borde de una realidad "inter-media" -existencia fronteriza hecha de un silencio de tiempo y una extrañeza de marco que crea la "imagen" discursiva en la encrucijada de la historia y el arte-, pero también es vínculo entre los lugares de enunciación y el mundo (Bhabha: 1994:17).

Desde aquí el creador indígena reclama nuevos imaginarios, nuevas formas de representación, es decir, establecer lugares de negociación y renegociación que permitan reinscribir sus signos, formas o conceptos, distintivos tanto del territorio de partida como del de llegada. Las formas estéticas propias del arte indígena se encuentran conexas con los dispositivos del arte actual. Sin embargo en ese sistema de evidencias sensibles se observa al mismo tiempo la existencia de un común, y el recorte que define sus lugares y partes respectivas.

Ticio Escobar propone que "el arte indígena no puede ser desprendido limpiamente de su afuera. Para trabajar sus contenidos intensos precisa de la belleza o la poesía, requiere argumentos formales estéticos que facilitan la defensa del sentido. Pero el arte no queda atrapado en esos alegatos (éstos no son autónomos); sus recursos formales se encuentran orientados siempre a una firme pragmática social y existencial, y abiertos a un ámbito ontológico. El arte indígena puede saltar de la escena de la representación: los actores no representan divinidades: son divinidades. Entonces, sí, por un instante, el arte puede trasponer la última

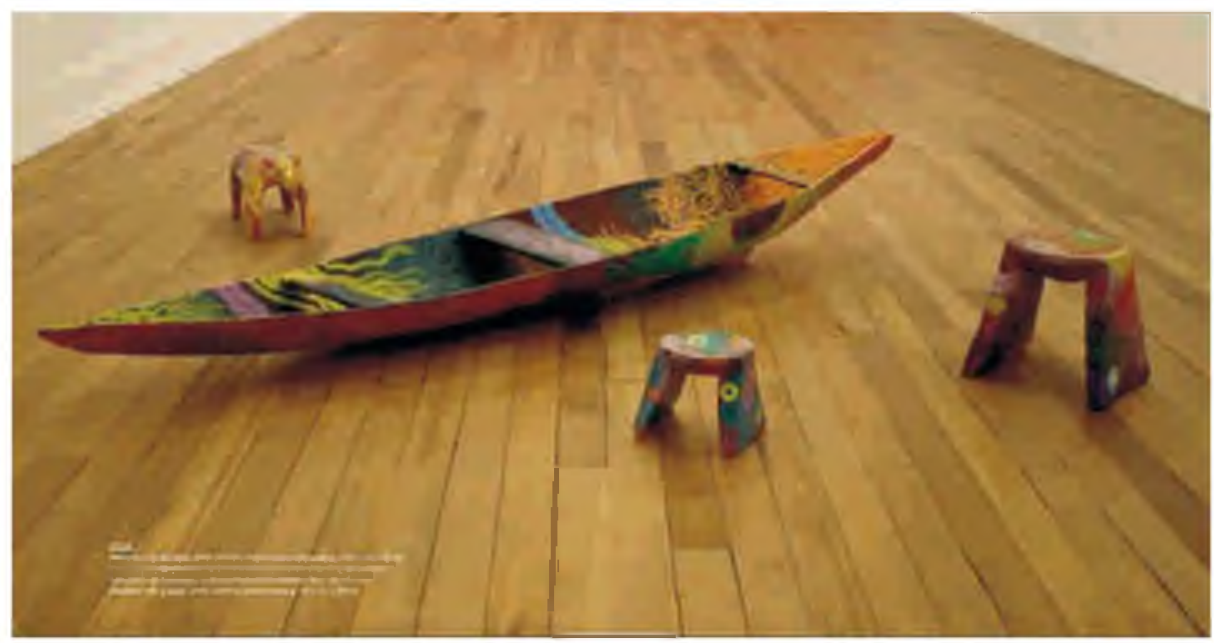

Benjamin Jacanamijoy, 2009. ${ }^{6}$

6 - Jacanamijoy, Benjamín.

https://s-media-cache-ak0.pinimg.com/originals/da/e0/d6/dae0d689301bfcd50bad1422c4ad38fc.jpg. Consultado:05/18/2015 
frontera y rozar, que no atrapar, lo absoluto. Todo arte siempre aspira a cruzar el marco: a nombrar lo real imposible" (Ramos, 2012).

Por eso el artista es en verdad la fuente de la experiencia y del saber que le posibilitan interpretar su posición originaria a la luz de la diversidad con la cual entra en contacto. Es la divinidad capaz de reconocer sus propias teorías estéticas, de traspasar las barreras de la cultura dominante para preservar la exclusividad de su territorio. Por eso se considera que el arte indígena introduce contrastes, rupturas, borra fronteras para irrumpir en los nuevos escenarios del arte.

En este escenario se comercializan ahora técnicas entre sí, ideas e imágenes se abrevian con resignación o entusiasmo en el concierto del capital simbólico cada vez más indiferenciado, desde donde se participa del festín global o de sus migajas. Sin embargo sería entonces necesario romper con las ataduras de la historia del arte occidental, para abrir un nuevo capítulo derivado de las experiencias construidas a partir de la mirada de pueblos hasta hoy desdibujados por las políticas de la Modernidad.

El arte indígena es también ese mundo extraño en donde juegan papeles importantes las fuerzas y los poderes sobrenaturales dotados de impulsos ciegos semejantes a los de las propias fuerzas de la naturale$\mathrm{za}$, esas que pretenden dar cuenta tanto de las marcas como de los olvidos; de las ausencias y de las supresiones vivenciadas en el mismo lugar de enunciación. El arte indígena no nace por su propia voluntad, sino que es llamado a ser y constituirse sobre la base de su capacidad de encontrar las dimensiones del pasado y del futuro en el presente, en lugares otros. Las intervenciones de este arte se vuelven legítimas no sólo cuando se ha insertado en la cadena del consenso internacional, sino también cuando se afirma en la existencia con las comunidades.

Por razones evidentes Adolfo Colombres considera el "arte indígena como un modelo superior y lo es por su mayor coherencia simbólica, que favorece el análisis comparativo y la búsqueda de la especificidad" (Colombres, 1991). Tales situaciones no significan para Colombres caer en un análisis reduccionista ciego a las aportaciones realizadas a través del tiempo por otras culturas. Más bien pretende, al tratar el arte indígena como un modelo superior, borrar las márgenes que lo separan de los distintos lugares de enunciación del arte, concederle importancia a sus formas y significaciones, las cuales responden a las condiciones de existencia y de producción de la comunidad desde donde se legitima.

Por eso la coexistencia de estas otras maneras de pensar el arte están en capacidad de discutir abiertamente con el concepto de contemporaneidad que se utiliza en la actualidad, así como de ingresar otras contemporaneidades que suelen armonizarse con cada una de las realidades diversas desde donde se gestan las producciones artísticas de los diferentes artistas con ascendencia indígena de la Región.

Tal es el caso de Carlos Jacanamijoy, un individuo perteneciente a un grupo de los tantos discriminados en Colombia (por su raza, religión, clase social, o lugar de nacimiento). Lejos de su ancestral cultura de origen pinta unos cuadros que, de seguro y de una manera u otra, reflejan su infancia, y están destinados a circular bajo las condiciones del gusto y del mercado que "uniforman" a todos los que se someten a ellas para ser juzgados, no por sus peculiaridades personales sino por la calidad de su producto.

Sin embargo Jacanamijoy, a través de su obra, busca reconfigurar lo representado, deshace sus confusiones a cambio de crear otras confusiones a partir de cuerpos y voces que se enhebran para desplegarse y transformarse en una melodía, una danza, un relato literario, en un diálogo; en un recorte de espacios y tiempos, de lo visible e invisible, de la palabra y del ruido que definen a la vez el lugar y lo que está en juego en la política como forma de experiencia. La poética de la resistencia, evidenciada en la obra de Jacanamijoy, revive la memoria de muchos pueblos del Sur de Colombia.

En esta dirección se plantean las prácticas artísticas del indígena como un espacio de confrontación en el cual se cruzan diversas alternativas de significación que se resisten a ser enunciadas desde las razones de los centros. La visión del artista indígena propone una poética diferente, una forma particular de simbolizar los elementos y fenómenos del cosmos, e invita al espectador a entrar en los laberintos de creación y reflexión. La variabilidad y diferenciación -técnica, estilística y temática- del artista indígena abre la posibilidad de considerarlo no sólo como un ser marginado y humillado sino también como un creador, un productor de imágenes, un sujeto sensible, creativo, capaz de aportar nuevas significancias al patrimonio simbólico universal.

Pero, ¿dónde radica hoy lo nuevo "de lo nuevo" de la producción indígena? Quizás sea en el carácter de discurso mutante y migrante, esto es, caracterizado por la incorporación de estrategias heterogéneas de enunciación y representación, y la ampliación del repertorio a través de nuevos soportes que superan el concepto mismo del arte.

Semejantes cambios de percepción requieren rupturas significativas donde las viejas líneas de pensamiento sean interrumpidas, las constelaciones más antiguas desplazadas, y los elementos -viejos y nuevos- reagrupados en torno a un esquema distinto de premisas y de temas. Desde esta perspectiva resultan prioritarias las discusiones que brinden herramientas para mirar el presente del arte indígena actual desde una dimensión crítica, dada su potencial condición emancipadora en el marco del debate de necesidades estéticas, artísticas y culturales en el contexto latinoamericano $y$, específicamente, en el espacio colombiano donde encontramos un número significativo de creadores empíricos y 


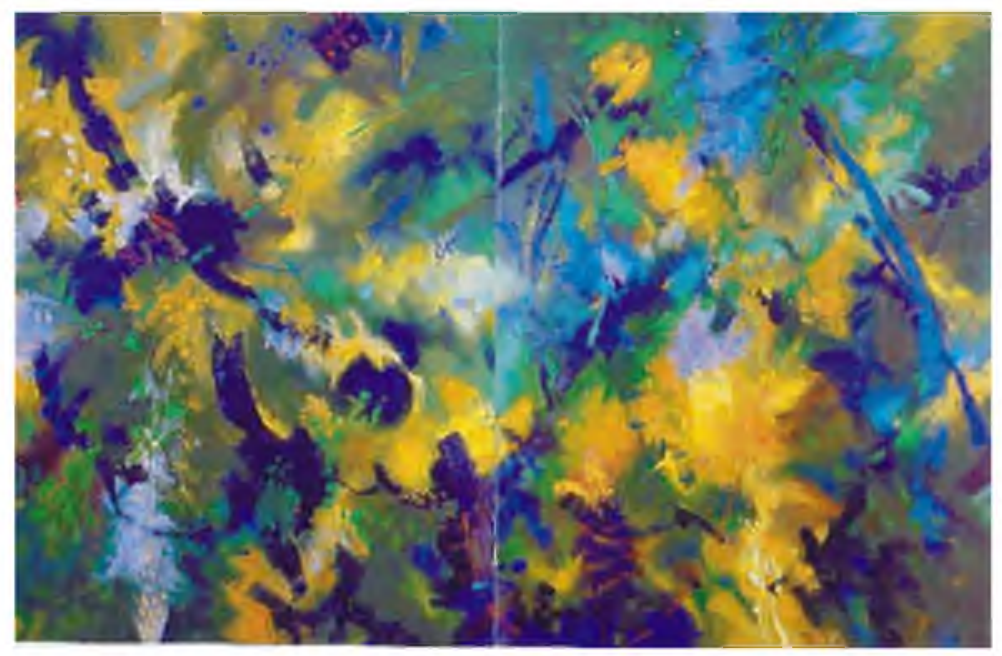

De un viejo atavío. Carlos Jacanamijoy, $1995^{7}$

con formación profesional de ascendencia indígena, quienes conservan y agencian su cultura desde los mismos lugares de enunciación.

\section{Referencias}

Azcuy, Eduardo. Kusch. El pensar desde América. Buenos Aires: Fernando García Cambeiro.

Betancourt, Fornet de (1985). Problemas actuales de la filosofía en Hispanoamérica. Buenos Aires: Ediciones FEPAI.

Bhabha, H. y Homi k H. (1994). El lugar de la cultura. Buenos Aires: Manantial.

Colombres, Adolfo (1991). Mitos, ritos y fetiches. Hacia una teoría americana del arte. Buenos Aires: Ediciones Del Sol.
Colombres, Adolfo; Acha Juan y Escobar, Ticio (2001). Hacia una teoría americana del arte. Buenos Aires: Del Sol.

Escobar, Ticio. Identidades en tránsito. Centro Teórico Cultural. En: http://www.pacc.ufrj.br/artelatina/ticio.html.

Escobar, Ticio (2012). "Arte Latinoamericano inmediato, WKTK 2012 Entrevista al arte latinoamericano inmediato. Paraguay. 10 de octubre de 2012

Guash, Ana María (2005). "Una historia cultural de la posmodernidad y del postcolonialismo. Lo intercultural entre lo global y local". Artes la Revista. Universidad de Antioquia, Facultad de Artes. no. 9 vol. 5. enero-junio.

Kusch, Rodolfo (1975). Geocultura del hombre americano. Buenos Aires: Colección Estudios Latinoamericanos.

Ramos, Julio (2012). La contemporaneidad de Ticio Escobar. En 80 Grados. 31 de agosto de 2012. 